\title{
Sobre o verdadeiro valor dos valores: fatores de impacto sobre as atitudes de tolerância política ${ }^{1}$
}

\author{
Eva-Maria Trüdinger \\ Universität Stuttgart, Alemanha
}

\begin{abstract}
Resumo
A pesquisa norte-americana sobre tolerância tradicionalmente discute a influência da educação sobre a tolerância política. Esses debates são transferidos para o contexto alemão e o artigo tenta complementar as pesquisas anteriores sobre tolerância com uma combinação de explicações baseadas em valores e descobertas sobre os sistemas de crença de massa e sobre as heurísticas na tomada de decisão. Supõese que os níveis de educação e sofisticação política de uma pessoa determinam sua atitude de tolerância política, pois causam um impacto sobre a relevância dos valores e das disposições ideológicas enquanto princípios abstratos para decisões individuais em situações de tolerância. Como resultado de nossa análise empírica, enfatizamos a influência separada da sofisticação política e a natureza contextual das atitudes tolerantes, em parte devido a diferenças individuais no manuseio dos princípios abstratos.
\end{abstract}

Palavras-chave: valores, tolerância política, sofisticação política, psicologia política.

\begin{abstract}
:
American tolerance research traditionally discusses the influence of education on political tolerance. These debates are transferred into a German context, and the article aims to complement previous research on tolerance by a combination of value-based explanations, of findings about mass belief systems and about heuristics in decision-making. It is assumed that the levels of education and political sophistication of a person determine his/her attitudes on political tolerance, because they have an impact on the relevance of values and ideological dispositions as abstract principles for individual decisions on tolerance situations. As a result of our empirical analyses, we can emphasize the separate influence of political sophistication and the contextual nature of tolerant attitudes, partly due to individual differences in the handling of abstract principles.
\end{abstract}

Key words: values, political tolerance, political sophistication, political psychology

\footnotetext{
1 Este artigo se baseia em um trabalho mais completo, publicado na Alemanha: TRÜDINGER, E.-M. Vom Wert der Werte: Erklärungsmodelle für Einstellungen politischer Toleranz. Frankfurt am Main u.a.: Peter Lang, 2006.
} 


\section{Introdução}

Em sociedades pluralistas, a tolerância, mais do que uma expressão na moda, é uma forma de coexistência humana que está no centro de muitos debates filosóficos e políticos. As atitudes quanto à tolerância política estão relacionadas com o funcionamento do sistema não somente social, mas também político.

No centro da definição de tolerância política está a aprovação de direitos civis iguais para todos os membros de uma comunidade política, inclusive aqueles que expressam idéias não-convencionais ou cujo comportamento não se conforma às normas sociais. A aceitação da diversidade (por meio da liberdade de opinião, por exemplo) é uma garantia essencial para a formação da opinião democrática e para a existência de alternativas políticas e oposição (DAHL, 1971). Ao mesmo tempo, uma dificuldade particular na investigação desse tema é o assim chamado paradoxo da tolerância: há limites para o que deve ser tolerado, a intolerância em relação ao intolerante pode ser necessária. A tolerância política não pode ser considerada um objetivo absoluto a alcançar. As atitudes tolerantes, por sua vez, são multidimensionais e dependentes do grupo e das atividades que devem ser toleradas. Este artigo examinará a tolerância política na Alemanha e suas fontes ou determinantes, com base no conhecimento das pesquisas norte-americanas sobre tolerância, uma vez que há poucas pesquisas sobre o tema na Europa.

Uma extensa literatura identifica a influência da educação sobre a tolerância política, e os argumentos a favor e contra suas conseqüências positivas sobre a disposição para tolerar têm sido debatidos com freqüência. Este artigo dá continuidade a esse aspecto: supõe-se que os graus de instrução e de conhecimento de uma pessoa determinam suas atitudes de tolerância política porque causam um impacto sobre a relevância dos valores e das disposições ideológicas. Eles funcionam como princípios abstratos para decisões individuais em situações de tolerância. Os valores são concepções do desejável e podem servir de referência para o indivíduo, mas a importância e a hierarquia entre diferentes valores podem diferir segundo as circunstâncias. Esta é provavelmente uma das razões para a natureza contextual e a diversidade das atitudes tolerantes.

Para destacar os mecanismos existentes entre princípios abstratos, educação e formação de atitudes, e traçar diferentes hipóteses, este artigo se concentra em duas abordagens alternativas sobre o modo como os cidadãos compreendem o mundo político. De um lado estão as bem conhecidas propostas de Converse (1964) sobre sistemas de crenças de massa. Do outro, pesquisas recentes em psicologia política voltam a enfatizar as diferenças nas tomadas de decisões individuais. Sniderman, Brody e Tetlock (1994a e 1994b) destacam a importância da sofisticação política como uma variável determinante do impacto das heurísticas (tais como valores e disposições ideológicas) sobre as atitudes. 
Este texto procura complementar pesquisas anteriores sobre tolerância com uma combinação de explicações centradas em valores e descobertas da psicologia cognitiva, e discute as seguintes questões: como as orientações baseadas em valores e as disposições ideológicas se relacionam com as atitudes de tolerância política? E como a educação e a sofisticação política influenciam essa relação?

Portanto, o artigo tem três objetivos principais. Em primeiro lugar, testar a influência direta das prioridades individuais de valores, medidas por uma escala de conformismo e conservadorismo (KLAGES, 1985), bem como das disposições ideológicas, medidas pela auto-classificação em uma escala esquerda-direita. Além das pesquisas existentes sobre tolerância, as explicações da tolerância política baseadas em valores são testadas. A análise controlará os efeitos de outros determinantes relevantes da tolerância mencionados na literatura, em especial a confiança social como uma heurística alternativa. Em segundo lugar, comparar a influência relativa da educação e da sofisticação política sobre as atitudes tolerantes e enfatizar a influência separada da sofisticação política, em particular como uma variável que representa a proximidade da vida política. Por fim, o artigo se concentra na interação dos princípios abstratos com a educação e a sofisticação política.

Para alcançar esses objetivos, será inicialmente apresentado o debate sobre o conceito de tolerância política e suas várias explicações, em especial o nexo entre educação e tolerância. Será então explicado como as orientações baseadas em valores e as disposições ideológicas individuais podem se relacionar com atitudes tolerantes e com a instrução e a sofisticação política de uma pessoa. As hipóteses serão seguidas pela ilustração dos dados e medidas. Finalmente, a análise empírica será apresentada e os resultados discutidos.

\section{O conceito de tolerância política}

No trabalho pioneiro de Stouffer, Comunismo, conformidade e liberdades civis (1955), a tolerância é vista como o grau em que as pessoas aceitam que grupos não-conformistas exerçam direitos democráticos procedimentais. Essa perspectiva é mais ampla do que a de Sullivan et al. (1979, p. 784) que definem tolerância como "uma disposição para 'suportar' aquelas coisas que se rejeita". A definição de Stouffer vai à raiz da questão ao afirmar que as diferenças individuais nos atributos e opiniões pessoais não devem ser um obstáculo ao exercício dos direitos políticos iguais e não devem provocar exclusão ou retirada da liberdade e da igualdade política (FORST, 2000; NUNN et al., 1978).

A análise das atitudes de tolerância política deve levar em conta que a tolerância per se nem sempre é desejável e que algum grau de intolerância em relação 
a pessoas intolerantes pode ser necessário para preservar um sistema existente de normas e valores (democráticos) (MARCUSE, 1988; SNIDERMAN et al., 1996). Por exemplo, as pessoas podem recusar direitos civis a extremistas de direita e, desse ponto de vista, as atitudes intolerantes de uma pessoa não indicam necessariamente uma falta de virtudes democráticas. Ao contrário, esse "paradoxo da intolerância" (SULLIVAN et al., 1982, p. 9) ilustra que as decisões de tolerar resultam freqüentemente da referência a valores conflitantes em situações diferentes. Isso complica a explicação das atitudes em relação à tolerância política. Hoje, não se espera automaticamente uma consistência entre tolerância como princípio abstrato e atitudes tolerantes dependentes de situações (ao contrário do que acontecia em pesquisas anteriores, por exemplo, Prothro e Grigg, 1960, e McClosky, 1964). Em vez disso, a própria ligação entre princípios abstratos e orientações específicas é analisada na pesquisa sobre tolerância política (GIBSON e BINGHAM, 1982; JACKMAN, 1978; NEVITTE, 1996; SNIDERMAN et al., 1989).

A dimensionalidade da tolerância política está relacionada com esse tema. Os defensores da "tese da unidade" (SNIDERMAN, 1993, p. 229) estimam que a tolerância política não depende dos grupos ou atividades a serem toleradas (SNIDERMAN et al., 1989; BOBO e LICARI 1989). Supõe-se que as atitudes em relação às atividades e grupos em questão afetam as decisões de tolerar de uma pessoa (CORBETT, 1982; HERSON e HOFSTETTER, 1975; LAWRENCE, 1976; WAGNER, 1986). Por exemplo, espera-se que as atitudes tolerantes em relação a diferentes grupos variem dependendo da posição desses grupos no espectro ideológico (SULLIVAN et al., 1979 e 1982; MCCLOSKY e BRILL, 1983; MCCUTCHEON, 1985). Tudo considerado, as explicações da tolerância política devem levar em conta os grupos e as atividades a serem toleradas.

\section{Explicações da tolerância política}

\section{Explicações baseadas em valores}

A maioria das explicações da tolerância política está centrada em determinantes como idade, emprego, status, gênero e instrução, mas carecem com freqüência de um fundamento teórico explícito. Explicações alternativas da tolerância política baseadas em valores são escassas, embora permitam referências ao contexto cultural de um país e relacionar a pesquisa sobre atitudes tolerantes a explicações centradas em traços pessoais, como autoritarismo ou dogmatismo (ROKEACH, 1960; SULLIVAN et al., 1981 e 1982). Golebiowska (1995) vincula valores modernos e educação à tolerância política, e Sniderman e seus associados (1996) explicam a aprovação dos direitos democráticos por hierarquias de valores individuais. 
Diferentemente das atitudes, os valores possuem um caráter abstrato e sua existência não depende de situações específicas. Um valor pode ser definido como "uma concepção, explícita ou implícita, distintiva de um indivíduo ou característica de um grupo, do desejável que influencia a seleção de modos, meios e fins de ação disponíveis" (KLUCKHOHN, 1962, p. 395). Como elementos centrais dos sistemas de crenças individuais, as orientações de valores afetam atitudes específicas, por exemplo, opiniões sobre imigrantes. Localizados no nível mais alto de generalização, esses "padrões avaliativos" (WILLIAMS, 1979, p. 16; ROKEACH, 1968, p. 550) ou "padrões de comparação" (ROKEACH, 1968, p. 551) ajudam os indivíduos a articular preferências, reduzir a complexidade individual e coletiva e tomar decisões (FEATHER, 1995; FELDMAN, 1988). Eles servem como "geradores de consistência" (SNIDERMAN, 1993, p. 225) e ajudam os indivíduos a deduzir diferentes opiniões a partir dos mesmos princípios subjacentes. Porém, atitudes específicas não podem ser derivadas diretamente de um certo valor, porque há valores em competição dentro de um sistema de crenças relevante para a tomada de decisão individual.

Tal como as orientações valorativas, as disposições ideológicas podem ser consideradas como princípios gerais que determinam atitudes específicas de tolerância política. Elas indicam o posicionamento do indivíduo no mundo político e as clivagens políticas tradicionalmente determinam os padrões ideológicos em uma sociedade. Esquerda e direita são consideradas posições dentro dessas clivagens e "instrumentos que os cidadãos podem usar para se orientar em um mundo político complexo" (FUCHS e KLINGEMANN, 1999, p. 203; FUCHS e KÜHNEL, 1990). Comparadas com os valores sociais, as disposições ideológicas estão mais relacionadas com as questões políticas e, portanto, seu uso presume provavelmente uma capacidade mais forte de abstração e uma maior consciência dos debates políticos.

Educação como passaporte para a tolerância?

O mito da educação como criadora de seres humanos melhores (e mais tolerantes) mascara mecanismos indiretos responsáveis pela ligação entre instrução e tolerância. Podemos conceber vários efeitos da educação sobre as atitudes de tolerância política.

Efeitos diretos - Durante muito tempo, considerou-se que a educação influenciava as atitudes tolerantes somente de maneira direta. As escolas, enquanto instituições centrais de socialização, facilitam o contato com grupos diversificados e ajudam os jovens a aceitar que as regras e liberdades são importantes para que grupos majoritários e minoritários vivam juntos (STOUFFER, 1955; DYNES, 1967; HAGENDOORN, 1999). Desse ponto de vista, a educação relaciona-se também com 
uma visão mais ampla do mundo e com uma diminuição do preconceito (HOPF, 1999). Porém, os processos de educação e socialização são mais complicados. Por exemplo, eles podem depender de características institucionais. Jackman e Muha (1984) sustentam mesmo que os mais instruídos são mais tolerantes apenas superficialmente (para críticas a esse argumento ver, por exemplo, Vogt, 1997, p. 50).

Efeitos indiretos - Sullivan et al. (1981 e 1982) consideram que a educação influencia a tolerância política indiretamente, por intermédio de seu impacto sobre a ideologia política bem como sobre normas e princípios gerais. De acordo com essa perspectiva, pode-se supor que alguns valores que promovem a tolerância política, como o universalismo e a solidariedade, são cada vez mais partilhados ou ativados em níveis de instrução mais elevados (WEIL, 1985; STOKER, 2001; HEYDER, 2003).

Pode-se também supor que a educação altera o conhecimento e a consistência das atitudes, e pode mudar o modo como se formam as atitudes e como as pessoas tomam decisões: "O conhecimento influencia como se pensa sobre tolerância política, não apenas o que se pensa" (VOGT, 1997, p. 137). Como exemplo, a educação pode aumentar a capacidade de considerar princípios abstratos de tolerância se supormos sua propriedade de promover consistência cognitiva (SNIDERMAN e GOULD, 1999; GAASHOLT e TOGEBY, 1995; LAWRENCE, 1976). Os recursos empíricos também sustentam o argumento oposto que sugere que a educação aumenta a diferença entre valores de tolerância e atividades específicas em relação à tolerância política de minorias (JACKMAN, 1978; NEVITTE, 1996). Os mais instruídos têm provavelmente visões de mundo mais complexas e modos de raciocinar influenciados não somente por princípios abstratos, mas também por questões factuais concomitantes ou informações contextuais.

Educação, não; sofisticação política, sim?

Um motivo da posição central que a educação assume na explicação da tolerância política é o fato de que ela representa e mede mecanismos mais complicados. Esses padrões podem ser divididos em dois grupos. De um lado, temos a competência geral de uma pessoa, isto é, capacidades cognitivas, conhecimento e o modo como ela manipula a informação em geral; a educação representa a "exposição à informação e o treinamento no uso de conhecimento conceitual" (JACOBY, 1991, p. 182). De outro, existem capacidades relacionadas com aspectos políticos; podemos discernir a consciência política e o modo de tratar conceitos e informações políticas como um fator que influencia a tolerância política. Essa dimensão pode ser chamada de sofisticação política (BOBO e LICARI, 1989; ZALLER, 1992; SNIDERMAN et al., 1994b). É importante distinguir essa capacidade de receber, comunicar e usar a 
informação política da educação. As duas dimensões estão relacionadas (ALMOND e VERBA, 1965; KLINGEMANN, 1979a), mas a sofisticação política está especialmente relacionada ao modo como vemos o mundo político. Somente a análise dos efeitos separados da sofisticação política sobre as atitudes de tolerância política pode discernir o "caráter político" das atitudes de tolerância política (SNIDERMAN et al., 1994b).

\section{Prioridades individuais de valores e disposições ideológicas como determinantes das atitudes}

Para explicar atitudes tolerantes por disposições ideológicas e valores, estes últimos vinculam-se aos argumentos concernentes à educação e à sofisticação política e estão integrados em teorias e análises mais gerais sobre sistemas de crenças e processos de decisão dos indivíduos.

A natureza dos sistemas de crença de massa (CONVERSE, 1964)

Converse introduziu na ciência política o conceito de sistema de crença individual e o definiu como "uma configuração de idéias e atitudes em que os elementos estão amarrados por algum tipo de constrangimento ou interdependência funcional" (1964, p.207). Seus componentes estão entrelaçados em uma estrutura em que "algum valor abstrato ou (...) posturas mais elevadas (...) funcionam como uma espécie de cola para unir muitas outras atitudes e crenças específicas, e essas posturas têm centralidade primordial no sistema de crença como um todo" (CONVERSE, 1964, p. 211). Um sistema de crença individual estrutura-se quando alguém deriva permanentemente atitudes específicas de princípios gerais subjacentes. Em um sistema de crença estruturado, supõe-se que as atitudes de tolerância política estão relacionadas e derivam de valores abstratos e de disposições ideológicas, independentemente do grupo e das atividades a serem julgadas. $\mathrm{Na}$ concepção de Converse, quanto mais informado é o indivíduo, mais a estrutura de sistema de crenças depende de princípios gerais e abstratos (CONVERSE, 1964, p. 213). O grau de informação, por sua vez, resulta da educação da pessoa e de seu interesse em um tópico. Portanto, é necessário verificar se a educação, a sofisticação política e o uso ativo de conceitos ideológicos exercem influência semelhante sobre a estrutura dos sistemas de crença. Em referência ao tema deste artigo, isso significa que educação e sofisticação política provavelmente têm um impacto na relação entre princípios abstratos e atitudes de tolerância política. Seguindo Converse, deveria-se supor que somente uma minoria de pessoas (por exemplo, a elite política) se baseia em princípios abstratos para formar suas opiniões quanto a questões de tolerância política, enquanto que a maioria dos cidadãos usa referências mais simples para 
tomar decisões (CONVERSE, 1964, p. 214). Portanto, temos de esclarecer se os valores e as disposições ideológicas medidos podem ser tratados do mesmo modo que os princípios abstratos de Converse.

O papel da heurística no raciocínio político (SNIDERMAN et al., 1994b)

Sniderman e seus associados tentam responder à questão - levantada implicitamente por Converse - de como é "possível que os cidadãos, tendo em vista como conhecem pouco sobre política, não obstante, conseguem freqüentemente ter uma idéia daquilo de que são politicamente a favor ou contra" (SNIDERMAN et al.,1994b, p. 18). As pessoas podem tomar decisões razoáveis apesar da falta de informação e de capacidade de compreender fatos políticos complexos. Esse problema, chamado de "enigma de Simon", é resolvido pelos autores pela suposição de que os cidadãos usam heurísticas na sua tomada de decisões: "Heurísticas constituem atalhos de julgamento, modos eficientes de organizar e simplificar as escolhas políticas, eficientes no duplo sentido de que exigem relativamente pouca informação para executar, mas produzem respostas confiáveis até mesmo para problemas complexos de escolha" (SNIDERMAN et al., 1994b, p. 19). Ao contrário do uso de princípios abstratos defendido por Converse, essas heurísticas podem ajudar as pessoas sem competência política (isso não significa que a falta de conhecimento seja compensada....). Essa abordagem enfatiza a importância de heurísticas menos baseadas em conhecimento, como emoções ou valores (SNIDERMAN et al., 1994b; SNIDERMAN, 2000; KUKLINSKI e QUIRK, 2000).

Igualmente importante para nossa explicação da tolerância política é o argumento central dos autores de que a escolha individual de heurísticas no processo de tomada de decisão está relacionada com seu nível de sofisticação política. Cidadãos menos instruídos e menos informados tendem a usar principalmente heurísticas emocionais; os mais instruídos compõem sua opinião com a ajuda de heurísticas mais baseadas em conhecimento (SNIDERMAN et al., 1994b). Em relação ao nosso tema, é necessário descobrir se as concepções do desejável e as disposições ideológicas podem ser consideradas atalhos baseados em conhecimento ou "heurísticas fáceis" (HURWITZ e PEFFLEY, 1992, p. 397) quando há pouca informação disponível.

Seguindo os autores, pode-se supor que valores e disposições ideológicas são menos importantes para as decisões sobre tolerância política quando o grau de educação aumenta: quanto mais informada a pessoa, mais fatores concomitantes ela leva em conta na tomada de decisão e menos importantes são os princípios gerais (por exemplo, o valor de auto-desenvolvimento). Essa distância entre a aprovação de um princípio geral e atitudes específicas é chamada de "enigma da política de princípios” (SNIDERMAN et al., 1994a; KUKLINSKI et al., 1991). 


\section{Tolerância política e valores particulares, disposições ideológicas e confiança social: uma conexão significativa?}

Prioridades valorativas - Para descrever e medir dimensões importantes dos sistemas de valores individuais, a análise se baseia na obra de Helmut Klages (1983, 1985 e 1993). Seguindo a divisão entre valores tradicionais e novos, ele diferencia dois grupos de valores, os de "dever e aceitação", de um lado, e valores de "auto-desenvolvimento", do outro. Os valores da primeira dimensão, os assim chamados "valores KON", são disciplina, conformidade, cumprimento de obrigação, ordem etc., conduzem a atitudes conservadoras, conformistas e convencionais. A dimensão do auto-desenvolvimento (os assim chamados "valores não-KON") inclui valores como participação, democracia, autonomia, proveito e auto-atualização (KLAGES 1983; 1993). Ainda que as duas dimensões tendam a ter uma correlação negativa, o sistema de valores de um indivíduo consiste freqüentemente de uma síntese de valores KON e não-KON (KLAGES, 1985). Pode-se esperar que sistemas de valores extremamente mistos têm um papel menor na formação da opinião, em relação a questões de tolerância política do que sistemas de valores mais uniformes.

Supõe-se que as orientações de valores KON favorecem atitudes razoavelmente intolerantes, ao passo que valores não-KON tendem a causar a aprovação da tolerância: uma pessoa que atribui importância à conformidade e à segurança provavelmente rejeitaria minorias não-conformistas, temendo contestações à ordem estabelecida (SNIDERMAN et al., 1996). Valores não-KON representam a disposição de tolerar a participação, a igualdade e a autonomia de todos os grupos sociais; as diferenças podem ser percebidas como enriquecimento. Porém, se a auto-atualização e a participação de grupos agressivos entra em conflito com a disposição de aceitar o auto-desenvolvimento de outros grupos nãoconformistas, os defensores do auto-desenvolvimento e da participação pode exibir atitudes intolerantes. Em situações como essa, os valores são considerados guias de orientação menos apropriados.

Disposições ideológicas - Os diversos elementos de significação referentes às disposições ideológicas podem ser agrupados em uma dimensão esquerda-direita que indica o posicionamento que um indivíduo faz de si mesmo no mundo político (CONOVER e FELDMAN, 1981; CHUBB et al., 1994; SCARBROUGH, 1995). A história política e os processos de construção de clivagens formaram a compreensão de "esquerda" e "direita" do seguinte modo: 
"Com esquerda, queremos significar a defesa da mudança social no sentido de uma maior igualdade - política, econômica, social; com direita, queremos significar o apoio a uma ordem social tradicional mais ou menos hierárquica e a oposição à mudança no sentido de uma maior igualdade" (LIPSET et al., 1954, p. 1135).

Porém, é necessário não esquecer que o significado do esquema esquerdadireita pode mudar no decorrer do tempo quando surgem novas clivagens - por exemplo, relacionadas com valores de auto-desenvolvimento. Ademais, não podemos fazer suposições definitivas sobre o significado das disposições ideológicas devido às diferenças individuais ao relacionar elementos de significado à dimensão esquerda. direita (CONOVER e FELDMAN, 1981). Não obstante, como essa dimensão pode estar associada às atitudes relacionadas com a tolerância política? Os defensores da esquerda tendem a exigir direitos iguais, tais como liberdade de opinião para todos e equalização das posições sociais. Pode-se afirmar que os cidadãos que se posicionam na direita querem conservar o status quo e são, portanto, contrários à mudança social. Supõe-se que sejam mais intolerantes em relação a grupos estrangeiros ou diferentes (HALMAN e HEINEN, 1996).

Confiança social como um atalho de julgamento alternativo? - Tal como a tolerância política, a confiança social lança luz sobre a relação de uma pessoa com seus "concidadãos" (OFFE, 1999, p. 42). Assim, os dois fatores podem ser relacionados e os trabalhos sobre tolerância política integram, às vezes, a confiança social em seus modelos explicativos (SULLIVAN et al., 1982; NEVITTE, 1996). Atuando como uma idéia positiva da humanidade, a confiança social pode promover atitudes positivas de tolerância política. As pessoas que confiam tendem provavelmente a esperar que os grupos tolerados não as desapontarão:

\footnotetext{
"Confiar é acreditar que os resultados da ação de outrem serão apropriados do nosso ponto de vista. (...) Pode-se dizer que a confiança baseia-se na crença de que a pessoa, que tem um grau de liberdade para desapontar nossas expectativas, cumprirá uma obrigação em todas as circunstâncias sobre as quais ela tem controle" (MISZTAL, 1996, p. 24).
}

Desse modo, a confiança social pode servir de guia de orientação alternativo para valores em conflito etc., no domínio da tolerância política. Porém, temos de esclarecer se a influência da confiança social relaciona-se igualmente com o nível de informação da pessoa: enquanto os proponentes do conceito "racional" de confiança social enfatizam sua dimensão cognitiva, outros supõem que ela pode 
orientar pessoas quando elas carecem de mais informações sobre uma situação (HARDIN, 1999; LAHNO, 2002). Quando alguém está confiando, suas atitudes de tolerância política são provavelmente menos determinadas por outras heurísticas, como orientações de valores ou disposições ideológicas.

\section{Hipóteses}

Diferentes hipóteses podem ser deduzidas dos argumentos relacionados com a pesquisa sobre valores, sistemas de crenças e sofisticação política que foram ilustrados:

H1 As orientações baseadas em valores e as disposições ideológicas têm um impacto sobre atitudes de tolerância política.

H2 Quanto mais uma pessoa é orientada para valores KON (valores não-KON), menos (mais) ela é politicamente tolerante.

H3 Quanto mais a pessoa é ideologicamente voltada para a esquerda (direita), mais (menos) ela é politicamente tolerante.

H4 Quanto mais alto o nível de educação e sofisticação da pessoa, maior é a probabilidade de que ela terá uma atitude positiva de tolerância política.

H5 Um nível mais elevado de instrução e sofisticação política implica um maior (menor) impacto das orientações baseadas em valores e disposições ideológicas sobre as atitudes de tolerância política da pessoa.

H6 Educação e sofisticação política não influenciam atitudes de tolerância política da mesma maneira; a sofisticação política tem uma influência mais forte sobre a tolerância política do que a educação.

É, portanto, incerto que $\mathrm{H} 1$ seja confirmada: Converse supõe que somente uma minoria de cidadãos tem sistemas de crenças estruturados por "posturas mais elevadas" (CONVERSE, 1964, p. 211), tais como valores, e que as atitudes de tolerância política em particular podem depender de sentimentos em relação aos grupos alvos que deverão ser tolerados ou de outros atalhos de julgamento, como a confiança social. Do mesmo modo, supõe-se que o dilema da "intolerância em relação ao intolerante" restringe a influência dos valores e disposições ideológicas como guias de orientação em questões de tolerância política. Os resultados de H4 e H5 confirmarão ou não os pressupostos tirados de Converse e de Sniderman et al. sobre a influência direta e indireta da educação e da sofisticação política sobre atitudes tolerantes. Ao mesmo tempo, eles ajudam a classificar os valores e conceitos ideológicos usados neste estudo como heurísticas mais ou menos dependentes de conhecimento. Nem Converse, nem Sniderman e seus associados 
diferenciam entre graus de educação e níveis de informação e consciência política. H6 afirma que a educação serve com freqüência de substituta para a sofisticação política, mas não pode ser equiparada a ela; a integração da sofisticação política ao modelo de explicação provavelmente capta de modo mais preciso os mecanismos que conduzem a atitudes mais tolerantes. A Figura 1 resume as relações discutidas.

Figura 1

Tolerância política: uma visão geral das relações discutidas

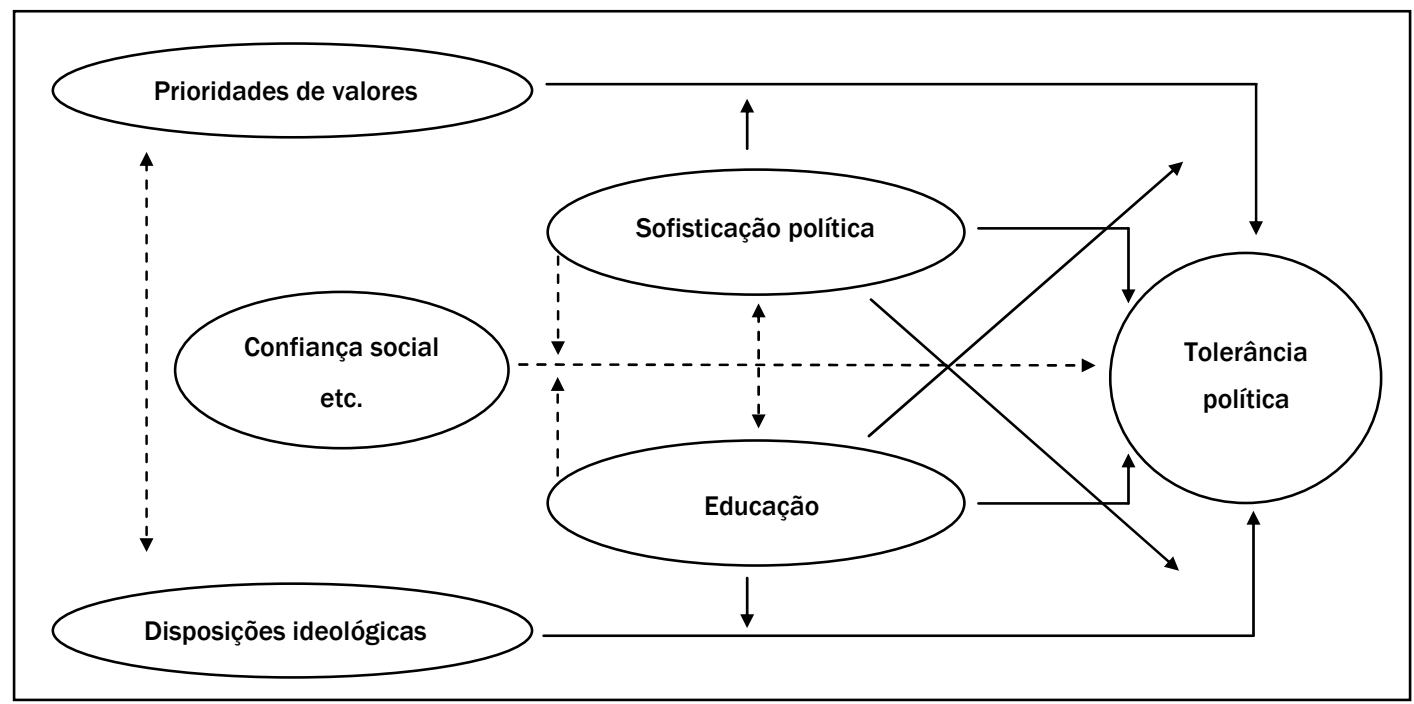

Fonte: Compilação da autora

\section{Dados e medidas}

As análises empíricas serão baseadas em dados de um projeto chamado "Cidadania, Envolvimento, Democracia" (CED), survey realizado em doze países europeus em 2000/2001. A análise se concentra nos 3.004 respondentes que moram na Alemanha; para assegurar a representatividade dos resultados, os dados estão estatisticamente ponderados.

Tolerância política - Ela pode ser medida por uma pergunta sobre a disposição dos respondentes a aceitar o exercício de uma liberdade civil essencial - liberdade de 
reunião - por vários grupos não-conformistas ${ }^{2}$. A escala de tolerância indicará então o grau em que os diferentes grupos são tolerados quando exercem essa atividade. $A$ questão tem por modelo a medida de Stouffer do "grau de disposição a tolerar nãoconformistas" (STOUFFER, 1955, p. 21). Stouffer perguntou se ateus, comunistas e socialistas deveriam ter permissão para falar em público, lecionar etc. Essa operacionalização foi criticada por Sullivan e seus associados, que propuseram perguntar pela disposição a aceitar os direitos de um grupo "menos querido". Porém, essa assim chamada "medida de conteúdo controlado" deve ser rejeitada (Sullivan et al. 1979, 1981 e 1982) porque não consegue mapear um fenômeno geral da tolerância (WAGNER, 1986). Ao mesmo tempo, essa concepção de intolerância é estreita demais porque pressupõe sentimentos negativos em relação a um grupo (GIBSON, 1992, p. 562).

Os diversos debates científicos sobre como medir atitudes de tolerância política dão razão à expectativa de dificuldades na comparação dos resultados nesse campo de pesquisa. Porém, Gibson observa que a tolerância política "parece ser uma atitude tão estável e fundamental dos cidadãos que é relativamente fácil de medir, mesmo com técnicas que são, à primeira vista, bastante diferentes" (1992, p. 572). A pergunta do survey CED representa uma versão aperfeiçoada da escala de Stouffer porque os grupos alvos listados cobrem um grande espectro ideológico e social. As posições ideológicas dos respondentes e dos grupos alvos podem, portanto, ser levados em conta. Além disso, a escala está localizada em um nível relativamente baixo de abstração e controla o contexto das atitudes de tolerância política (NEVITTE, 1996; SNIDERMAN et al., 1996). Não obstante, não devemos esquecer que as respostas dos pesquisados sobre questões de tolerância foram influenciadas pelos fatores contextuais da época em que a pesquisa foi realizada e por um "viés de aceitabilidade social". Este viés tem provavelmente impacto sobre a relação entre educação e tolerância política se os mais instruídos escolhessem a resposta "correta", aquela socialmente aceita (JACKMAN, 1978; CORBETT, 1982).

Os cidadãos alemães são menos tolerantes em relação a extremistas de direita (33\%), seguidos pelos racistas (41\%), extremistas de esquerda (62\%) e fundamentalistas islâmicos (69\%). Todos esses grupos podem fazer uso da liberdade de reunião a fim de propagar opiniões políticas extremistas. As taxas de tolerância mais altas são encontradas em relação aos seguintes grupos alvos: pessoas de outra raça (96\%), imigrantes (94\%) e portadores de AIDS (94\%).

A fim de examinar a dimensionalidade de atitudes de tolerância política e classificá-las, foram realizadas várias análises fatoriais (Tabela 1), que confirmam a diferenciação que os respondentes fazem entre grupos "socialmente diferentes" e

\footnotetext{
2 A formulação exata da pergunta é a seguinte: "Você acha que algum desses grupos não deveria ter permissão para realizar reuniões públicas?" (lista dos grupos).
} 
minorias de um caráter mais político (NEVITTE, 1996, p. 63). As atitudes em relação a "pessoas com ficha criminal" não se encaixam nas duas dimensões observadas e são assim excluídas das análises (ver Fatorial 2 da Tabela 1). É interessante observar que os resultados não sugerem uma separação entre grupos esquerdistas e direitistas (MCCUTCHEON, 1985), nem a existência de uma dimensão específica de "tolerância inter-étnica" (GAASHOLT e TOGEBY, 1995, p. 265), tampouco a unidimensionalidade da tolerância política (BOBO e LICARI, 1989). Portanto, as análises seguirão com um índice de "tolerância política em relação a grupos políticos" e um índice de "tolerância política em relação a grupos sociais". É possível demonstrar que as pessoas são mais tolerantes com grupos sociais do que com grupos políticos (medida em uma escala de 0 a 1: médias de $0,57$ e 0,91$)$.

Tabela 1

Dimensões das atitudes de tolerância política (análise fatorial)

\begin{tabular}{|l|ccc|ccc|}
\hline & \multicolumn{3}{|c|}{ Fatorial 1 } & \multicolumn{3}{c|}{ Fatorial 2 } \\
\cline { 2 - 8 } & F 1 & F 2 & C. & F 1 & F 2 & C. \\
\hline Extremistas de esquerda & & 0,75 & 0,57 & & 0,75 & 0,58 \\
Extremistas de direita & $-0,19$ & 0,75 & 0,51 & $-0,18$ & 0,75 & 0,52 \\
Racistas & & 0,73 & 0,50 & & 0,73 & 0,50 \\
Fundamentalistas cristãos & 0,22 & 0,59 & 0,47 & 0,23 & 0,60 & 0,49 \\
Fundamentalistas islâmicos & 0,18 & 0,66 & 0,54 & 0,20 & 0,66 & 0,55 \\
Imigrantes & 0,81 & & 0,64 & 0,81 & & 0,65 \\
Pessoas de outra raça & 0,83 & & 0,67 & 0,83 & & 0,68 \\
Homossexuais & 0,78 & & 0,60 & 0,78 & & 0,61 \\
Pessoas com AIDS & 0,83 & & 0,67 & 0,83 & & 0,67 \\
Viciados em drogas & 0,60 & 0,13 & 0,42 & 0,59 & 0,13 & 0,41 \\
Pessoas com ficha criminal & 0,38 & 0,37 & 0,37 & & & \\
\hline Eigenvalues & $\mathbf{4 , 1}$ & $\mathbf{1 , 9}$ & & 3,8 & 1,9 & \\
F1 * F2 & & 0,30 & & & 0,27 & \\
Proporção de variância explicada & & $54 \%$ & & & $57 \%$ & \\
\hline
\end{tabular}

Nota: Análise fatorial (PCA, Oblimin). C.= comunalidades. F1, F2 = fatores 1, 2.

Fonte: Computado a partir do CED 2000-2001, Alemanha.

Valores, disposições ideológicas e confiança social - As orientações individuais baseada em valores são medidas indiretamente por meio de questões sobre como seria a sociedade desejada pelo respondente. De acordo com os argumentos teóricos de Klages e os itens disponíveis, são usadas questões sobre os princípios 
que as pessoas querem ver enfatizados numa sociedade ${ }^{3}$. Esses princípios podem ser classificados ao longo das dimensões de conformidade e não-conformidade. Baseado na dupla oposição "ordem versus participação" e "diligência versus autodesenvolvimento", é possível construir um índice de orientações baseada em valores KON e não-KON ${ }^{4}$ (GABRIEL e BRETTSCHNEIDER, 1997). As disposições ideológicas são medidas pelo auto-posicionamento dos respondentes em uma escala de onze pontos que vai da extrema esquerda à extrema direita ${ }^{5}$. Três perguntas estão disponíveis para medir a confiança social e estão na base do índice ${ }^{6}$.

Educação e sofisticação política - A educação é medida pelos anos de instrução do respondente. A sofisticação política, fator crucial nos argumentos de Converse e Sniderman et al., é chamada alternativamente de expertise política, complexidade cognitiva, sofisticação ideológica ou envolvimento (ZALLER, 1992; NEUMAN, 1986). Em geral, ela é usada como um conceito-feixe e pode ser definida como "uma tendência a dar atenção detalhada à política, ter à mão bancos de informações sobre política, compreender múltiplos argumentos (...), e reconhecer as interrelações entre esses argumentos" (SNIDERMAN et al., 1994b, p. 21). Sniderman e seus associados medem esse conceito por meio da variável educação, mas essa abordagem não está adotada aqui devido às diferenças afirmadas entre educação e o fator "mais político" da "sofisticação política".

Converse não define explicitamente esse conceito, e não está claro como ele o relaciona com "constrangimento" ou a questão de ser informado. Contudo, subordinando-se a Converse (1964), uma medida popular de sofisticação é indicar, por exemplo, a consistência das atitudes de um indivíduo em relação a uma determinada questão ou medida política por simples correlações entre itens. Admite-

\footnotetext{
3 Foram feitas as seguintes perguntas: "Agora vou ler algumas afirmações sobre como a sociedade poderia ser. Você pode me dizer para cada uma dessas afirmações se você gostaria de viver em ... uma sociedade que enfatiza que as pessoas sejam industriosas e diligentes (diligência)? ... uma sociedade que enfatiza que as pessoas se prendam às regras (ordem)? ... uma sociedade que enfatiza que as pessoas sejam politicamente ativas (participação)? ... uma sociedade que enfatiza que as pessoas possam se realizar (auto-desenvolvimento)?"

4 Os valores são medidos de acordo com o método de rating. Alguns pesquisadores criticam essa medida porque ela não reflete o caráter de preferência das prioridades de valor. Levando isso em conta e a fim de aumentar a variância, o índice é gerado calculando as diferenças de valores dos itens dois a dois.

5 “Em questões políticas, as pessoas falam em 'esquerda' e 'direita'. Como você colocaria suas opiniões nesta escala, em termos gerais?" Respostas em uma escala de 0 (esquerda) a 10 (direita).

6 Foram feitas as seguintes perguntas aos respondentes: "Em termos gerais, você diria que se pode confiar na maioria das pessoas ou que todo o cuidado é pouco ao tratar com as pessoas?"; "Você diria que, na maior parte do tempo, as pessoas tentam ser prestativas ou que elas cuidam principalmente delas mesmas?"; "Você acha que a maioria das pessoas tentaria levar vantagem sobre você se tivesse a chance, ou tentaria ser justa?".
} 
se que quanto maiores forem as correlações, maior é o grau de sofisticação do respondente (CONVERSE, 1964; NIE e ANDERSEN, 1974; JUDD e MILBURN, 1980). Um dos problemas desse método de mensuração (WYCKOFF, 1987; KNIGHT, 1985) pode ser ilustrado com a seguinte objeção: atitudes consistentes não estão inevitavelmente relacionadas a um nível mais alto de consciência ou compreensão políticas, mas podem ser o resultado do uso de enquadramentos comuns ou atalhos de julgamento; "a consistência é espúria, emergindo da dependência das atitudes em relação às experiências comuns a partir de pontos de referência" (LUSKIN, 1987, p. 869).

Tendo em vista essas dificuldades na mensuração, usamos a relação proposta entre sofisticação política e a questão de ser informado em política, e nos baseamos na definição de sofisticação política como "o grau em que um indivíduo dá atenção aos eventos políticos correntes e compreende o que encontrou" (ZALLER, 1990, p. 126). Isso reflete a dimensão cognitiva da cultura política no conceito de Almond e Verba (1965), a saber, o envolvimento político. Esse fator agrupa vários componentes relacionados com a reunião e a exposição à informação política - por exemplo, o conhecimento de uma pessoa sobre política, seu interesse sobre política e sua competência política subjetiva. A sofisticação política pode assim ser medida com a ajuda dessa abordagem e ainda estar de acordo com as considerações teóricas de Sniderman et al. e Converse (NEUMAN, 1986). Nesse caso, é possível usar questões sobre conhecimento político ${ }^{7}$, interesse político ${ }^{8}$, uso político da mídia ${ }^{9}$ e competência política subjetiva ${ }^{10}$ para medir a sofisticação política. As análises fatoriais confirmam que esses fatores residem em uma única dimensão e podem, em

\footnotetext{
7 A seguinte questão foi usada para medir o conhecimento político: "Quantos países-membros tem a União Européia (UE)?" Porém, é necessário ter consciência dos limites desse método porque a questão mede um conhecimento especial sobre a UE.

8 Foi construído um índice de interesse político, combinando duas perguntas relevantes para as dimensões de interesse político objetivo e subjetivo (VAN DETH, 1990). Interesse político subjetivo: "Em geral, o quanto você se interessa por política? Você diria que está muito interessado, razoavelmente interessado, não muito interessado ou nada interessado?". Respostas: Muito interessado, razoavelmente interessado, não muito interessado ou nada interessado. Interesse político objetivo: "Com que freqüência você diria que discute questões políticas com outras pessoas?". Respostas: Freqüentemente, às vezes, raramente, nunca.

${ }^{9}$ O uso político da mídia é medido por uma escala de três itens baseada nas seguintes perguntas: "Com que frequêencia você ... lê o conteúdo político de um jornal? ... escuta ou vê noticiários no rádio ou televisão? ... escuta ou vê outros programas sobre política e questões sociais no rádio ou televisão?". Respostas: Todos os dias, 3.4 dias por semana, 1.2 dias por semana, com menos freqüência, nunca.

10 Para medir "o grau em que os indivíduos pensam que podem influenciar o governo" (ALMOND e VERBA, 1965, p. 139), foram usadas as seguintes questões e construiu-se um índice de competência política subjetiva: "As pessoas como você têm maior ou menor possibilidade do que outras de apresentar suas opiniões aos políticos? As pessoas como você têm maior ou menor possibilidade do que outras de fazer com que os políticos levem em consideração suas opiniões?" Respostas em uma escala de 0 (muito menor) a 10 (muito maior).
} 
conseqüência, ser agrupados em um índice de sofisticação política. As análises fatoriais também demonstraram que a educação tem de ser tratada separadamente.

Variáveis de controle - Pesquisas anteriores indicaram que gênero, idade e grau de urbanização do local de residência devem ser levados em conta. Ao fazê-lo, a importância relativa dos principais determinantes para o desenho da pesquisa pode ser avaliada ${ }^{11}$.

\section{Análises e resultados}

A influência direta das orientações baseadas em valores e das disposições ideológicas

Para obter uma primeira impressão da relevância empírica das relações postuladas teoricamente, foram realizadas análises de regressão, separadas conforme as duas dimensões da tolerância analisadas acima. Um resultado inicial foi a diferença observada entre as duas dimensões da tolerância política, que se destaca na comparação de todos os modelos e se repete em análises posteriores. Isso coloca em questão a obra de alguns autores que pressupõem que a tolerância tem um caráter unidimensional e que é independente dos grupos e atividades que devem ser tolerados.

Em termos globais, observa-se uma influência relativamente fraca dos valores e das disposições ideológicas sobre as atitudes de tolerância política (Tabela 2).

\footnotetext{
11 A urbanidade é medida por uma escala de seis itens que vai de áreas de residência extremamente rurais a áreas extremamente metropolitanas.
} 
Tabela 2

Modelo das fontes de atitudes de tolerância política

(coeficientes de regressão)

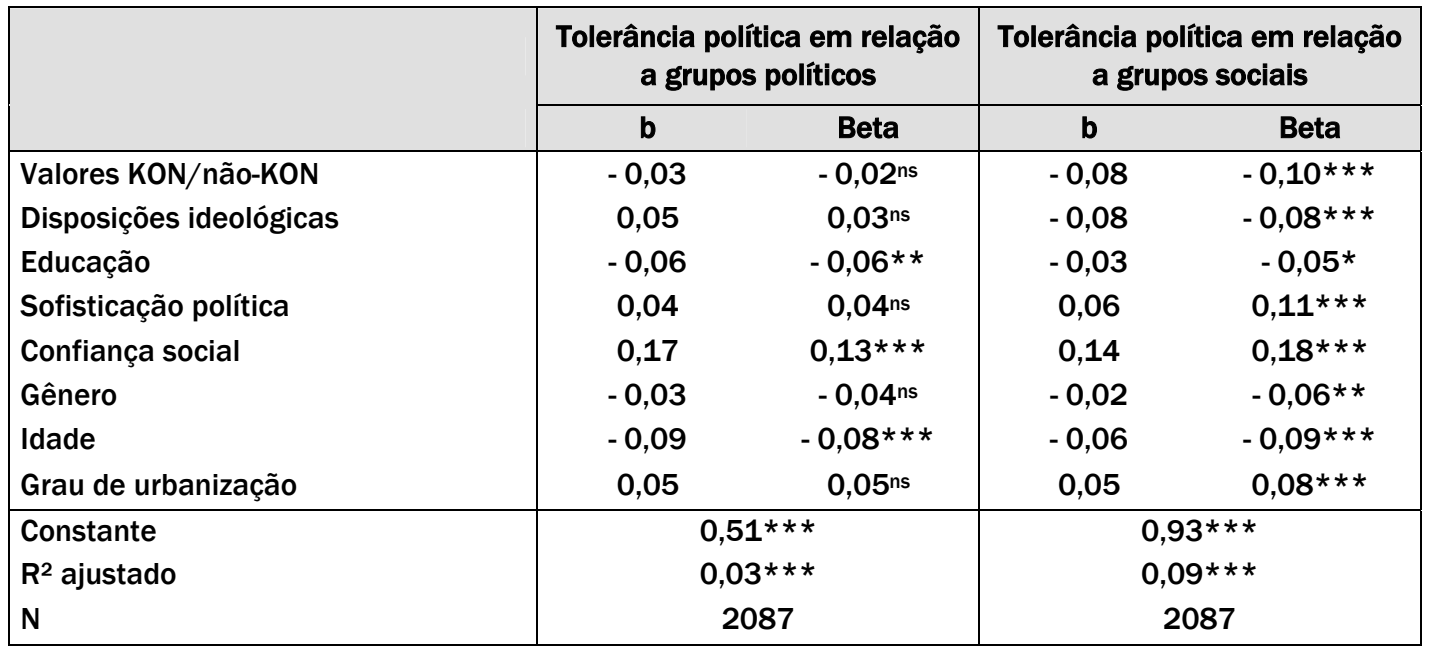

Nota: $*=p \leq 0,05 ; * *=p \leq 0,01 ; * * *=p \leq 0,001 ;$ ns $=$ estatisticamente não significante.

Fonte: Calculado a partir de CED 2000-2001, Alemanha.

Esses resultados parecem contradizer a primeira hipótese e terão de ser examinados mais de perto. O fraco poder explicativo do modelo não impõe diretamente outras explicações relacionadas com os fatores demográficos controlados (gênero, grau de urbanidade etc.), mas antes sugere que julgamentos de tolerância se baseiam em opiniões sobre grupos alvos, sentimentos pessoais ou confiança social. Esta última afeta bastante as atitudes tolerantes e parece validar as proposições sobre o papel da confiança social como uma heurística alternativa para julgamento. Porém, não se deve tirar conclusões apressadas quanto à relevância das "posturas mais elevadas" em geral, pois outros valores como "liberdade" ou "igualdade" poderiam estar mais relacionados com o tópico da tolerância política. Além disso, pode-se supor que há efeitos importantes que resultam da interação entre valores, disposições ideológicas e outras variáveis, limitando o poder de explicação do modelo como um todo. Esta suposição tem o apoio dos resultados de análises de variância alternativas que indicam efeitos interativos, em particular entre orientações baseadas em valores, de um lado, e idade, gênero, educação e confiança social, de outro (esses modelos mostram entre $20 \%$ a $30 \%$ da variância explicada, incluindo os principais efeitos de interação).

As orientações baseadas em valores e as disposições ideológicas não influenciam a tolerância em relação a grupos políticos, mas influenciam a tolerância 
em relação a grupos sociais. Nesse território, as hipóteses 2 e 3 parecem ser confirmadas e, mais uma vez, encontram-se diferenças entre as duas dimensões das atitudes de tolerância política. Quanto mais uma pessoa se orienta por valores de conformidade e se inclina ideologicamente para a direita, menos ela demonstra tolerância política em relação a grupos sociais, mas não em relação a grupos políticos. Os proponentes da não-conformidade e da esquerda são mais tolerantes com grupos sociais.

Desse modo, como devemos interpretar os resultados fracos na explicação da tolerância política em relação a grupos políticos? Eles estão relacionados apenas parcialmente com o fato de que o índice combina grupos situados em posições diferentes do espectro ideológico e social: as mesmas análises foram feitas separadamente para vários grupos, tais como extremistas de direita e de esquerda, e os resultados realmente não melhoraram. Assim, devemos supor que essa limitação se deve a três outros aspectos. Em primeiro lugar, à dificuldade da tarefa incumbida ao respondente de decidir-se se deveria ou não tolerar os intolerantes, tais como extremistas políticos ou racistas (SNIDERMAN et al., 1996). Em segundo lugar, à íntima relação entre atitudes em relação a grupos sociais e concepções gerais de como a sociedade deveria ser. Por fim, a relação entre valores e disposições ideológicas, de um lado, e tolerância, do outro, é provavelmente curvilinear. É possível que pessoas da extrema-esquerda ou direita e com idéias extremamente conformistas ou não-conformistas sobre a sociedade tenham opiniões mais radicais sobre como tratar minorias do que cidadãos moderados. Isso poderia ser outra explicação para os baixos coeficientes que foram encontrados.

Os vieses da educação e da sofisticação política

A fraca influência encontrada das prioridades valorativas e das disposições ideológicas sobre a tolerância política, quando se considera a população como um todo, não contradiz as abordagens teóricas de Sniderman et al. e Converse. Ao contrário, dá suporte a considerações sobre diferenças no processo individual de tomada de decisões, dependendo do grau de informação ou educação da pessoa. Por esse motivo, deve-se analisar em modelos de regressão separados como as "posturas mais elevadas" medidas interagem com níveis de educação (Tabela 3) e de sofisticação política (Tabela 4) ${ }^{12}$.

\footnotetext{
12 Os respondentes foram divididos em três grupos representando os níveis baixo, médio e alto de educação e sofisticação política, respondendo por um número de casos nos grupos distribuídos, grosso modo, de maneira igual.
} 
Tabela 3

Modelos das fontes de atitudes de tolerância política (coeficientes de regressão), por níveis separados de educação

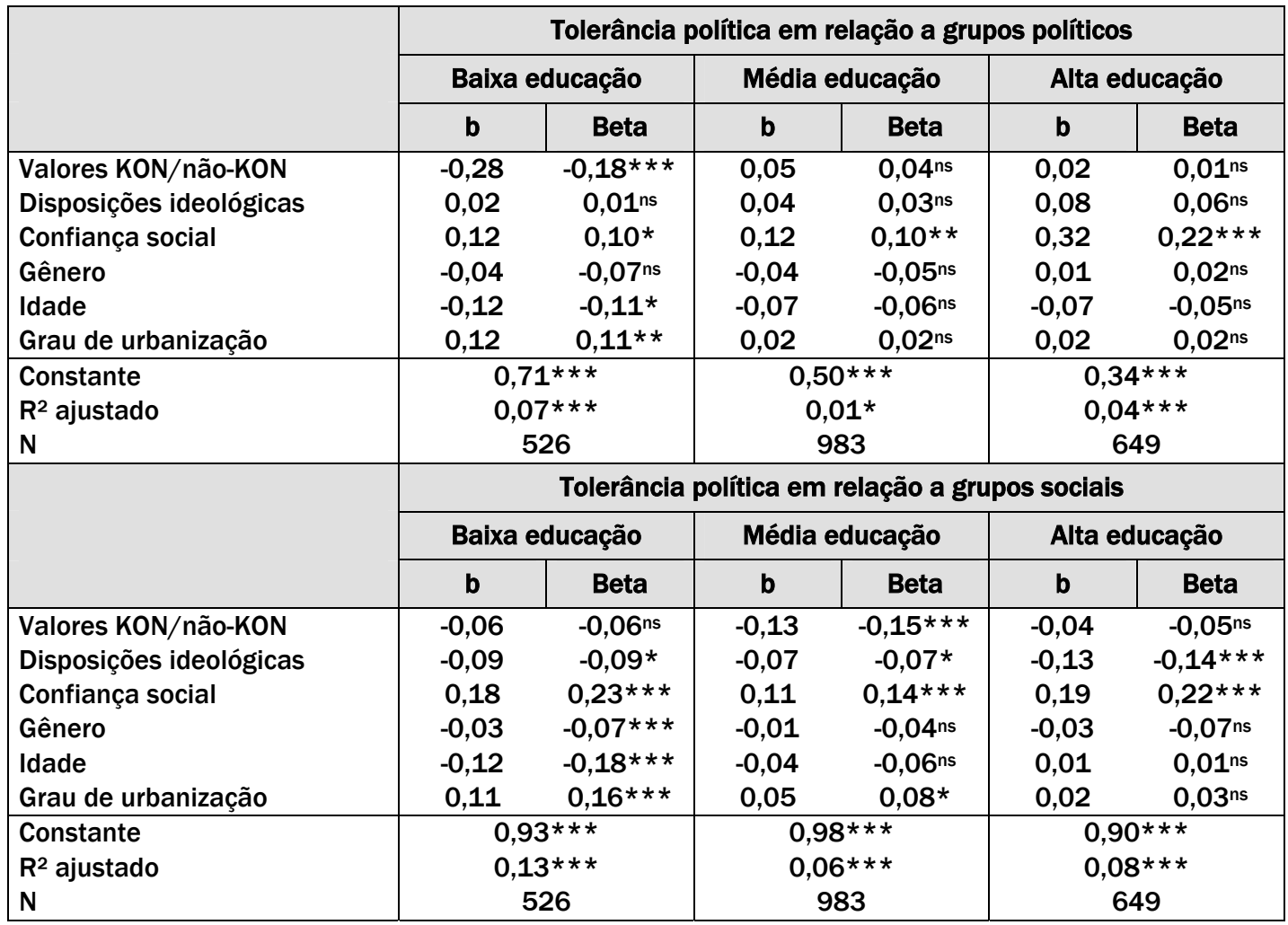

Nota: $*=p \leq 0,05 ; * *=p \leq 0,01 ; * * *=p \leq 0,001 ;$ ns $=$ estatisticamente não significante.

Fonte: Calculado a partir de CED 2000-2001, Alemanha.

De forma global, os modelos podem ser distinguidos quanto ao seu poder explicativo, que é muito maior quando se olha para o grupo que contém cidadãos menos informados e instruídos. A consciência política e a maior instrução levam a processos de decisão mais complexos que ainda não podem ser modelados? Ao olhar mais de perto a influência dos valores sobre a tolerância política a fim de examinar a hipótese 5, a questão parece se tornar ainda mais legítima. A influência de orientações baseadas em valores conformistas e não-conformistas sobre as atitudes tolerantes em relação a grupos políticos é mais decisiva para pessoas com níveis baixos de instrução e para pessoas com graus baixos de sofisticação política quando discutem atitudes em relação a grupos sociais (influência na direção proposta). Esse resultado parece contradizer aqueles que ligam o uso de princípios gerais com altos níveis de competência política. 
Desse modo, pode-se concluir também que os valores analisados não são semelhantes aos princípios abstratos, de acordo com Converse, mas servem antes como simples enquadramentos nas decisões cotidianas de uma pessoa (CHONG, 1996). Porém, as análises estão igualmente em concordância com a idéia do "enigma da política de princípios" (SNIDERMAN et al., 1994a): os valores desempenham um papel menor nas decisões de pessoas bem informadas porque têm de competir com uma multiplicidade de reflexões e considerações.

Tabela 4

Modelos de fontes de atitudes de tolerância política (coeficientes de regressão) por níveis separados de sofisticação política

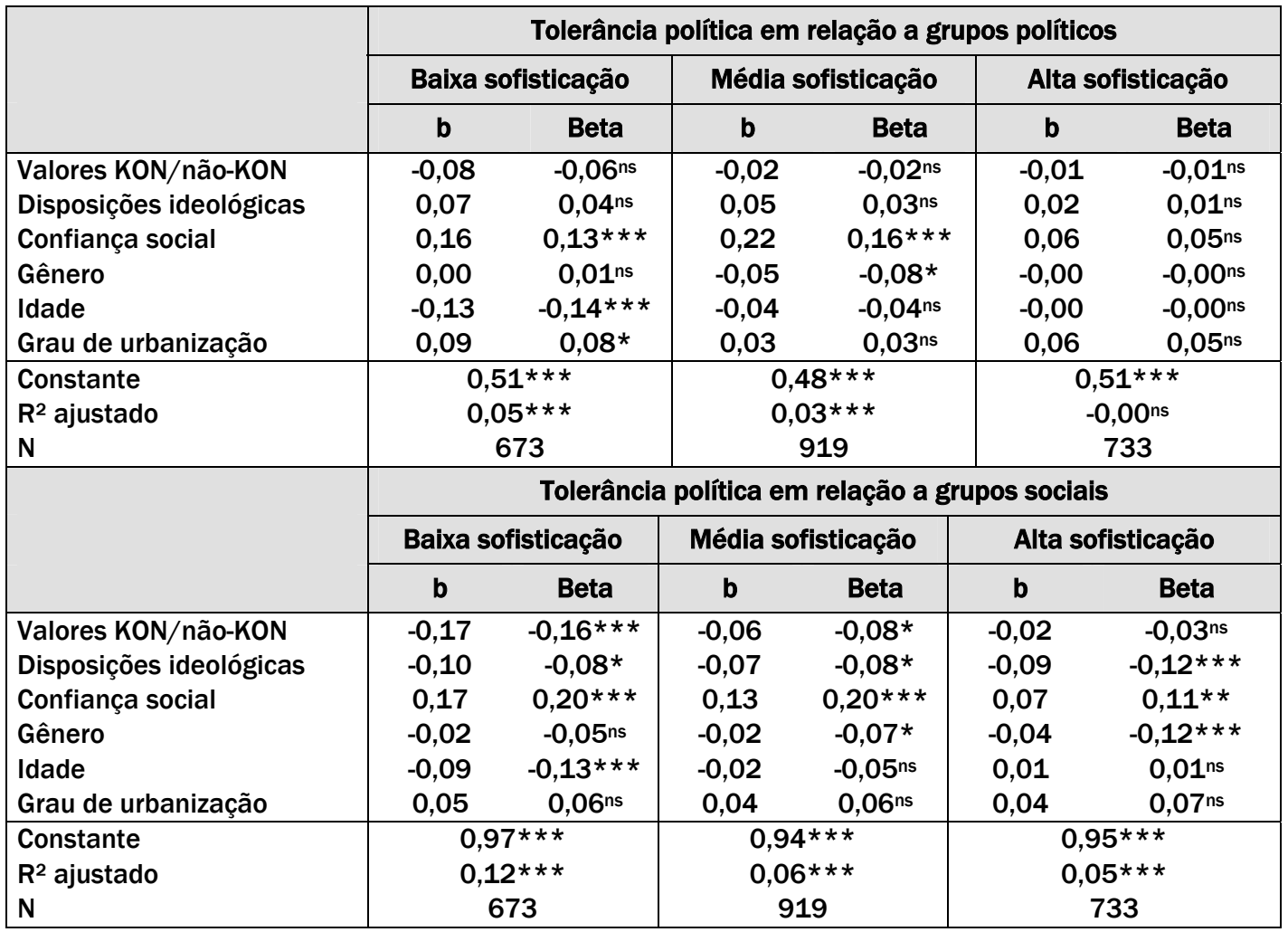

Nota: $*=p \leq 0,05 ; * *=p \leq 0,01 ; * * *=p \leq 0,001 ;$ ns $=$ estatisticamente não significante.

Fonte: Calculado a partir de CED 2000-2001, Alemanha.

As disposições ideológicas não podem ser consideradas do mesmo modo como os valores foram medidos. Elas não determinam como as pessoas pensam e sentem em relação a grupos políticos. Ao mesmo tempo, os resultados empíricos 
indicam que elas influenciam particularmente as decisões sobre tolerância política em relação a grupos sociais tomadas pelos cidadãos mais instruídos e mais sofisticados (Tabelas 3 e 4). Em conseqüência, parecem ser poucos princípios gerais que exigem um certo nível de conhecimento e consciência política quando usadas como heurísticas em questões de tolerância política.

Supondo-se que as diferenças na influência indireta dos valores e das disposições ideológicas não se devem exclusivamente aos diferentes métodos de mensuração dos dois conceitos, podemos dizer que as pessoas estão aparelhadas para diferentes tipos de heurísticas, resultado que está de acordo com conclusões recentes da psicologia política cognitiva (por exemplo, Chong, 1996; e Lupia et al., 2000, com outras referências).

Sniderman e seus associados já haviam descoberto que as pessoas usam heurísticas de julgamento variadas, dependendo da natureza da questão relevante e do nível de informação da pessoa. A confiança social é o fator que tem o maior impacto nas considerações sobre tolerância política e pode ser tomada como outro exemplo de heurística competindo com os valores medidos. Além disso, a influência positiva da confiança social sobre a tolerância política não se limita a opiniões sobre grupos sociais; afeta também de modo considerável os julgamentos sobre os direitos dos grupos políticos (Tabelas 2, 3 e 4). Ao contrário dos valores e das disposições ideológicas, este tipo de heurística parece ser mais geral e menos independente de grupos alvos ou valores conflitantes. Ao mesmo tempo, a relevância da confiança social não aumenta consistentemente com o aumento dos níveis de educação e sofisticação política. Assim, a confiança social pode ser considerada um quadro de referência mais geral e mais amplo.

Efeitos diretos da educação e da sofisticação política sobre a tolerância política

Ao enfocar os efeitos diretos (em vez dos indiretos) da educação e da sofisticação política sobre a tolerância política, as diferenças entre os dois fatores se tornam mais pronunciadas e parecem validar a hipótese 6 . Ao contrário do proposto na hipótese 3 , a educação tem pouca influência na tolerância política e confirma os argumentos a favor de outros determinantes dessas atitudes. Isso ocorre também porque a debilidade do efeito educacional não se deve a uma relação direta e próxima entre valores e educação ${ }^{13}$, como pensaram alguns pesquisadores. A Tabela 2 mostra que os mais instruídos são ainda mais intolerantes em relação a grupos sociais e políticos. Porém, em termos de tolerância política em relação a grupos políticos, isso pode ser entendido da seguinte maneira: é mais provável que as pessoas com alto

\footnotetext{
13 Evidências disso podem ser encontradas em simples correlações bivariadas entre valores e educação $\left(r=-0,11^{* * *}\right)$ e entre disposições ideológicas e educação $\left(r=-0,09^{* * *}\right)$.
} 
grau de instrução sejam mais capazes de ver um problema em tolerar minorias aparentemente intolerantes. Em termos gerais, a influência relativamente fraca da educação é inesperada e não reflete o lugar proeminente dessa variável nas pesquisas anteriores sobre tolerância.

É possível encontrar outras razões para deduzir os efeitos autônomos da educação e da sofisticação política. Não há mudanças importantes no poder explicativo dos dois fatores, estejam eles integrados separada ou simultaneamente em diferentes modelos estatísticos. Embora tenha sido encontrada uma relação positiva entre educação e sofisticação política $\left(r=0,23^{* * *}\right)$, os modelos de regressão validam os resultados das análises fatoriais e a hipótese 6: educação e sofisticação política parecem ser fatores independentes, ao contrário do proposto por Sniderman e seus associados.

Como evidência adicional, a sofisticação política está relacionada positivamente e de modo forte com a tolerância política em relação a grupos sociais do que a educação (Tabela 2): quanto mais alto o nível de sofisticação da pessoa, mais tolerante ela é com grupos sociais, ou seja, a hipótese 4 foi parcialmente confirmada. Além disso, esse padrão oferece uma prova do grau em que as atitudes medidas de tolerância política fazem referências à política ou a uma "dimensão política".

\section{Discussão e conclusões}

Em conclusão, é certamente possível observar uma influência dos valores e disposições ideológicas medidos sobre atitudes de tolerância política de acordo com as hipóteses deduzidas, mas é uma influência fraca que tem a ver principalmente com atitudes em relação a grupos sociais. Desse modo, os resultados não rejeitam completamente o modelo, na medida em que a relevância dos princípios orientadores testados depende claramente dos níveis de instrução e sofisticação política, como supõem abordagens teóricas apresentadas. Além disso, os resultados se baseiam na quantidade restrita de indicadores disponíveis na pesquisa CED. Por exemplo, a medida de tolerância política é apenas uma opção possível entre outras.

No conjunto, encontrou-se alguns indícios de que a tolerância política é um complexo multidimensional de atitudes (GIBSON e BINGHAM, 1982) e pesquisas futuras terão de examinar mais de perto a questão de como os cidadãos diferenciam entre "intolerância" em geral e uma "recusa a tolerar" (WAGNER, 1986, p. 45), usando eventualmente novas técnicas de experimentação (LUPIA et al., 2000). Ao mesmo tempo, as comparações em diversos países europeus poderiam analisar o impacto de culturas políticas nacionais específicas sobre atitudes tolerantes. 
A fraca relação entre a educação e as atitudes medidas de tolerância política dá suporte para a perspectiva alternativa, a qual focaliza o impacto dos valores. No entanto, também fornece incentivos a um foco sobre a natureza do viés educacional em outros domínios das atitudes políticas e sua relação com a questão da sofisticação política. Em qualquer caso, a perspectiva da psicologia cognitiva, ao colocar ênfase sobre a heterogeneidade de uma população e sobre as diferenças individuais nos processos de tomada de decisões, pode fundamentar a pesquisa convencional sobre atitudes políticas.

É necessário acrescentar outros detalhes referentes aos efeitos da sofisticação política sobre a tolerância política. Análises adicionais examinaram como componentes separados do índice de sofisticação política afetam a tolerância e descobriu-se que a competência política subjetiva desempenha um papel decisivo na determinação de atitudes de tolerância política. Esses resultados e as descobertas quanto à confiança social confirmam a relevância dos traços pessoais em questões relativas à tolerância política. Portanto, uma combinação de diferentes abordagens psicológicas, junto com a pesquisa sobre valores em ciência política, continuará a ser útil no futuro. 


\section{Referências Bibliográficas}

ALMOND, G. A.; VERBA, S. The civic culture: political attitudes and democracy in five nations. Boston: Little, Brown and Company, 1965.

BOBO, L.; LICARI, F. C. Education and political tolerance: testing the effects of cognitive sophistication and target group affect. Public Opinion Quarterly, v. 53, p. 285-308, 1989.

CHONG, D. Creating common frames of reference on political issues. In: MUTZ, D. C.; SNIDERMAN, P. M.; TETLOCK, R. A. Political persuasion and attitudes change. Ann Arbor: University of Michigan Press, 1996, p. 195-224.

CHUBB, J. E.; HAGEN, M. G.; SNIDERMAN, P. M. Ideological reasoning. In: SNIDERMAN, P. M.; BRODY, R. A.; TETLOCK, P. E. (ed.). Reasoning and choice: explorations in political psychology. Cambridge: Cambridge University Press, 1994, p. 140-163.

CONVERSE, P. E. The nature of belief systems in mass publics. In: APTER, D. E. (ed.). Ideology and discontent. Glencoe, Illinois: Free Press, 1964, p. 206-261.

CONOVER, P. J.; FELDMAN, S. The origins and meaning of liberal/conservative selfidentifications. American Journal of Political Science, v. 25, p. 617-645, 1981.

CORBETT, M. Political tolerance in America: freedom and equality in public attitudes. Nova York: Longman, 1982.

DAHL, R. A. Polyarchy: participation and opposition. New Haven: Yale University Press, 1971.

DYNES, W. Education and tolerance: an analysis of intervening factors. Social Forces, v. 46, p. 22.34, 1967.

FEATHER, N. T. Values, valences, and choices: the influence of values on the perceived attractiveness and choice of alternatives. Journal of Personality and Social Psychology, v. 68, p. 1135-1151, 1995.

FELDMAN, S. Structure and consistency in public opinion: the role of core beliefs and values. American Journal of Political Science, v. 32, p. 416-440, 1988.

FORST, R. Toleranz, gerechtigkeit, vernunft. In: FORST, R. (ed.). Toleranz: philosophische grundlagen und gesellschaftliche praxis einer umstrittenen tugend. Frankfurt: Campus, 2000. 
FUCHS, D.; KLINGEMANN, H.-D. The left-right schema. In: JENNINGS, M. K.; VAN DETH, J. (ed.). Continuities in political action. A longitudinal study of political orientations in three western democracies. Berlim: De Gruyter, 1990, p. 203-234.

FUCHS, D.; KÜHNEL, S. M. Die evaluative bedeutung ideologischer selbstidentifikation. In: KAASE, M.; KLINGEMANN, H.-D. (ed.). Wahlen und Wähler. Analysen aus Anlaß der Bundestagswahl 1987. Opladen: Westdeutscher Verlag, 1990, p. 217-252.

GAASHOLT, O.; TOGEBY, L. Interethnic tolerance, education and political orientation: evidence from Denmark. Political Behavior, v. 17, p. 265-285, 1995.

GABRIEL, O. W.; BRETTSCHNEIDER, F. Werte, ideologien und politikpräferenzen. In: GABRIEL, O. W.; BRETTSCHNEIDER, F.; VETTER, A. (ed.). Politische kultur und wahlverhalten in einer großstadt. Opladen: Westdeutscher Verlag, 1997, p. 43.68.

GIBSON, J. L.; BINGHAM, R. D. On the conceptualization and measurement of political tolerance. American Political Science Review, v. 76, p. 603-620, 1982.

GIBSON, J. L. Alternative measures of political tolerance: must tolerance be 'least-liked'? American Journal of Political Science, v. 36, p. 560-577, 1992.

GOLEBIOWSKA, E. Individual value priorities, education and political tolerance. Political Behavior, v. 17, p. 23-48, 1995.

HAGENDOORN, L. Introduction: a model of the effects of education on prejudice and racism. In: HAGENDOORN, L.; NEKUEE, S. (ed.). Education and racism: a cross national inventory of positive effects of education on ethnic tolerance. Aldershot: Ashgate, 1999, p. 1-19.

HALMAN, L.; HEINEN, T. Left and right in modern society. In: HALMAN, L.; NEVITTE, N. (ed.). Political value change in western democracies. Tilburg: Tilburg University Press, 1996.

HARDIN, R. Do we want trust in government? In: WARREN, M. E. (ed.). Democracy and trust. Cambridge: Cambridge University Press, 1999, p. 22-41.

HERSON, L.; HOFSTETTER, C. R. Tolerance, consensus, and the democratic creed: a contextual exploration. Journal of Politics, v. 37, p. 1007-1032, 1975.

HEYDER, A. Bessere bildung, bessere Menschen? Genaueres hinsehen hilft weiter. In: HEITMEYER, W. (ed.). Deutsche Zustände. Folge 2. Frankfurt: Edition Suhrkamp, 2003. 
HOPF, W. Ungleichheit der bildung und ethnozentrismus. Zeitschrift für Pädagogik, p. 847-865, 1999.

HURWITZ, J.; PEFFLEY, M. Traditional versus social values as antecedents of racial stereotypes and policy conservatism. Political Behavior, v. 14, p. 395-421, 1992.

JACOBY, W. G. Ideological identification and issue attitudes. American Journal of Political Science, v. 35, p. 178-205, 1991.

JACKMAN, M. R. General and applied tolerance: does education increase commitment to racial integration? American Journal of Political Science, v. 22, p. 302-324, 1978.

JACKMAN, M.; MUHA, M. J. Education and intergroup attitudes: moral enlightenment, superficial democratic commitment, or ideological refinement? American Sociological Review, v. 49, p. 751-769, 1984.

JUDD, C. M.; MILBURN, M. A. The structure of attitude systems in the general public: comparisons of a structural equation model. American Sociological Review, v. 45, p. 627-643, 1980.

KLAGES, H. Wertorientierung und staatsbezug: untersuchungen zur politischen kultur in der Bundesrepublik Deutschland. Frankfurt: Campus Verlag, 1983.

Wertorientierungen im wandel: rückblick, gegenwartsanalyse, prognosen. Frankfurt: Campus Verlag, 1985

Traditionsbruch als herausforderung: perspektiven der wertewandelsgesellschaft. Frankfurt: Campus Verlag, 1993.

KLINGEMANN, H. D. The background of ideological conceptualization. In: BARNES, S. H.; KAASE, M. et al. Political action: mass participation in five western democracies. Beverly Hills: Sage, 1979a, p. 255-277.

KLUCKHOHN, C. Values and value orientations in the theory of action. In: PARSONS, T.; SHILS, E. A. (ed.). Toward a general theory of action. New York: Horpers Publishers, 1962.

KNIGHT, K. Ideology in the 1980 election: ideological sophistication does matter. Journal of Politics, v. 47, p. 828-853, 1985. 
KUKLINSKI, J. H.; RIGGLE, E.; OTTATI, V.; SCHWARZ, N.; WYER, R. S. Jr. The cognitive and affective bases of political tolerance judgements. American Journal of Political Science, v. 35, p. $1 \cdot 27,1991$.

KUKLINSKI, J. H.; QUIRK, P. J. Reconsidering the rational public: cognition, heuristics, and mass opinion. In: LUPIA, A.; McCUBBINS, M. D.; POPKIN, S. L. (ed.). Elements of reason: cognition, choice, and the bounds of rationality. New York: Cambridge University Press, 2000.

LAHNO, B. Der Begriff des Vertrauens. Paderborn: Mentis Verlag, 2002.

LAWRENCE, D. G. Procedural norms and tolerance: a reassessment. American Political Science Review, v. 70, p. 80-100, 1976.

LIPSET, S. M.; LAZARSFELD, P. F.; BARTON, A. H.; LINZ, J. The psychology of voting: an analysis of voting behavior. In: GARDNER, L. (ed.). Handbook of social psychology 2. Reading: Addison-Wesley. S., 1954, p. 1124-1554.

LUPIA, A.; McCUBBINS, M. D.; POPKIN, S. L. (ed.). Elements of reason: cognition, choice, and the bounds of rationality. Nova York: Cambridge University Press, 2000.

LUSKIN, R. C. Measuring political sophistication. American Journal of Political Science, v. 31, p. 856-899, 1987.

MARCUSE, H. Repressive toleranz. In: WOLFF, R. P.; MOORE, B.; MARCUSE, H. Kritik der reinen toleranz. Frankfurt: Suhrkamp, 1988.

MCCLOSKY, H. Consensus and ideology in american politics. American Political Science Review, v. 58, p. 361-382, 1964.

MCCLOSKY, H.; BRILL, A. Dimensions of tolerance. Nova York: Basic, 1983.

MCCUTCHEON, A. L. A latent class analysis of tolerance for nonconformity in the american public. Public Opinion Quarterly, v. 49, p. 474-488, 1985.

MISZTAL, B. A. Trust in modern society: the search for the basis of social order. Cambridge: Polity Press, 1996.

NEUMAN, W. R. The paradox of mass politics: knowledge and opinion in the american electorate. Cambridge: Harvard University Press, 1986. 
NEVITTE, N. Tolerance and intolerance in advanced industrial states: the cross-time evidence. In: HALMAN, L.; NEVITTE, N. (ed.). Political value change in western democracies. Tilburg: Tilburg University Press, 1996, p. 59.79.

NIE, N. H.; ANDERSEN, K. Mass belief systems revisited: political change and attitude structure. Journal of Politics, v. 36, p. 540-591, 1974.

NUNN, C. Z.; CROCKETT, H. J.; WILLIAMS, J. A. Tolerance for nonconformity. San Francisco: Jossey-Bass Publishers, 1978.

OFFE, C. How can we trust our fellow citizens? In: WARREN, M. E. (ed.). Democracy and trust. Cambridge: Cambridge University Press, 1999, p. 42.87.

PROTHRO, J. W.; GRIGG, C. W. Fundamental principles of democracy: bases of agreement and disagreement. Journal of Politics, v. 22, p. 276-294, 1960.

ROKEACH, M. The open and the closed mind: investigations into the nature of belief system and personality systems. Nova York: Basic Books, 1960. 559, 1968.

The role of values in public opinion research. Public Opinion Quarterly, v. 32, p. 547.

SCARBROUGH, E. Materialist-postmaterialist value orientations. In: VAN DETH, J. W.; SCARBROUGH, E. (ed.). The impact of values. Beliefs in government. v. 4. Oxford: Oxford University Press, 1995, p. 123-159.

SNIDERMAN, P. M. The new look in public opinion research. In: FINIFTER, A. (ed.). Political science II. The state of the discipline. Washington, D.C.: American Political Science Association, 1993, p. 219.245.

Taking sides: a fixed choice theory of political reasoning. In: LUPIA, A.; MCCUBBINS, M. D.; POPKIN, S. L. (ed.). Elements of reason: cognition, choice, and the bounds of rationality. New York: Cambridge University Press, 2000, p. 67-84.

SNIDERMAN, P. M.; BRODY, R. A.; TETLOCK, P. E. (ed.). Reasoning and choice. Explorations in political psychology. Cambridge: Cambridge University Press, 1994a.

The role of heuristics in political reasoning: a theory sketch. In: (ed.). Reasoning and choice: explorations in political psychology. Cambridge: Cambridge University Press, 1994b, p. 14-30. 
SNIDERMAN, P. M.; FLETCHER, J. F.; RUSSELL, P. H.; TETLOCK, P. E. The clash of rights: liberty, equality, and legitimacy in pluralist democracies. New Haven: Yale University Press, 1996.

SNIDERMAN, P. M.; GOULD, E. R. Dynamics of political values: education and issues of tolerance. In: HAGENDOORN, L.; NEKUEE, S. (ed.). Education and racism: a cross national inventory of positive effects of education on ethnic tolerance. Aldershot: Ashgate, 1999, p. 137-161.

SNIDERMAN, P. M.; TETLOCK, P. E.; GLASER, J. M.; GREEN, D. P.; HOUT, M. Principled tolerance and the american mass public. British Journal of Political Science, v. 19, p. 25-45, 1989.

STOKER, L. Political value judgements. In: KUKLINSKI, J. H. (ed.). Citizens and politics: perspectives from political psychology. Nova York: Cambridge University Press, 2001, p. 433. 468.

STOUFFER, S. A. Communism, conformity, and civil liberties: a cross-section of the nation speaks its mind. Garden City, N.Y.: The Country Life Press, 1955.

SULLIVAN, J. L.; PIERESON, J. E.; MARCUS, G. E. An alternative conceptualization of political tolerance: illusory increases 1950s-1970s. American Political Science Review, v. 73, p. 781 . 794, 1979. 1982. Political tolerance and american democracy. Chicago: The University of Chicago Press, SULLIVAN, J. L.; MARCUS, G. E.; FELDMAN, S.; PIERESON, J. E. The sources of political tolerance: a multivariate analysis. American Political Science Review, v. 75, p. 92-106, 1981.

VAN DETH, J. W. Interest in politics. In: JENNINGS, M. K.; VAN DETH, J. (ed.). Continuities in political action: a longitudinal study of political orientations in three western democracies. Berlim: De Gruyter, 1990, p. 275-312.

VOGT, P. W. Tolerance and education: learning to live with diversity and difference. Thousand Oaks: Sage Publications, 1997.

WAGNER, J. Political tolerance and stages of moral development: a conceptual and empirical alternative. Political Behavior, v. 8, p. 45.80, 1986.

WEIL, F. D. The variable effects of education on liberal attitudes: a comparative-historical analysis of anti-semitism using public opinion survey data. American Sociological Review, v. 50, p. 458-474, 1985. 
WILLIAMS, R. Change and stability in values and value systems: a sociological perspective. In: ROKEACH, M. (ed.). Understanding human values. Individual and societal. New York: Mac Millan, 1979, p. 15-46.

WYCKOFF, M. L. Issues of measuring ideological sophistication: level of conceptualization, attitudinal consistency, and attitudinal stability. Political Behavior, v. 9, p. 193-224, 1987.

ZALLER, J. R. Political awareness, elite opinion leadership, and the mass survey response. Social Cognition, v. 8, p. 125-153, 1990.

. The nature and origins of mass opinion. Nova York: Cambridge University Press, 1992.

Recebido para publicação em novembro de 2005.

Aprovado para publicação em março de 2006.

Tradução de Pedro Maia Soares. 